\title{
A landscape view of cereal aphid parasitoid dynamics reveals sensitivity to farm- and region-scale vegetation structure
}

\author{
Michael J. BREWER ${ }^{1}$, Takuji NOMA ${ }^{1}$, Norman C. ElLIOTT ${ }^{2}$, AleXandra N. KRAVCHENKO ${ }^{3}$ and Ann L. HILD ${ }^{4}$ \\ ${ }^{1}$ Integrated Pest Management Program, Department of Entomology, CIPS Bldg, Michigan State University, East Lansing, \\ Michigan 48824, USA; e-mail: brewerm@msu.edu \\ ${ }^{2}$ U.S. Department of Agriculture, Agricultural Research Service, Plant Science Research Laboratory, Stillwater, \\ Oklahoma 74075, USA \\ ${ }^{3}$ Department of Crop and Soil Sciences, Michigan State University, East Lansing, Michigan 48824, USA \\ ${ }^{4}$ Department of Renewable Resources, University of Wyoming, Laramie, Wyoming 82071, USA
}

Key words. Aphididae, Braconidae, Aphelinidae, Diuraphis noxia, parasitoids, landscape ecology, scale, seasonality, grasslands, wheat, sunflower

\begin{abstract}
Functioning of plant-aphid-natural enemy interactions may be associated with the structure and composition of withinfield vegetation, neighborhood fields and field borders, and the regional plant community of cropped and noncropped areas. Farmand region-scale vegetation in the wheat-growing area of the North American Great Plains was hypothesized to effect the abundance of two hymenopteran parasitoids, that differ in physiological and behavioral attributes, of the key pest aphid of wheat, Diuraphis noxia (Mordvilko). The parasitoids had greater sensitivity to farm-scale vegetation (wheat strip rotation with or without spring-sown sunflower) than region-scale vegetation (degree of diversification with other crops and wheat fields converted to conservation grasslands). A two-way factorial design of scale (farm- and region-scale) revealed that parasitoid abundance in grass-dominant (homogeneous) areas especially benefited from adding sunflower to the wheat-fallow strip crop rotation. Considerable sensitivity of the analysis was added when adjusting for seasonality of vegetation, revealing that the region-scale effects were most prominent late season. From a management viewpoint, adding sunflower into the wheat production system, especially in relatively homogeneous vegetation regions, tends to promote local parasitoid populations during the summer when spring-sown plants are maturing and wheat is not in cultivation. Contrasting results for A. albipodus and L. testaceipes were consistent with expectations based on behavioral and physiological attributes of the two aphid parasitoid families they represent. Still, the general management interpretation seems robust for the two parasitoids and has relevance to both farm- and region-scale management schemes that are occurring in the wheat production zone of North American Great Plains.
\end{abstract}

\section{INTRODUCTION}

The structure and composition of vegetation may be important drivers in the functioning of plant-aphid-natural enemy interactions. It is well understood that key vegetation elements at the farm-scale may increase the impact of natural enemies, especially when the organisms have preferred resources derived from vegetation. As example, Cowgill et al. (1993) found flowering non-crop plants next to cereal crops increased abundance of adults and eggs of the syrphid Episyrphus balteatus (Degeer) in winter wheat, with nectar and pollen likely serving as the key resource additions used by the hover fly. Also in England, Vorley \& Wratten (1987) found barley and early-sown wheat adjacent to late-sown wheat served as a significant source of hymenopteran parasitoids (Aphidius spp.) to control cereal aphids on late-sown wheat. Aphids on the early grains were implicated as a key resource addition used by the parasitoid. And in the USA, Ahern \& Brewer (2002) found that addition of spring-sown sunflower into a strip rotation of winter wheat and fallow increased abundance of several hymenopteran parasitoids (Braconidae and Aphelinidae) that attack a key pest aphid on wheat. Sunflower had extra-floral nectaries and har- bored non-pest aphids within the host range of these parasitoids (Noma et al., 2005; Rogers, 1985).

Is region-scale structure and composition of vegetation also relevant, either jointly with or in isolation of the influence of vegetation at the farm-scale? Thies et al. (2005) in Germany found that higher aphid parasitism was found in agricultural lands nested in diverse regional vegetation than in agricultural lands nested in simpler regional vegetation, although this beneficial effect was offset by higher aphid colonization in areas of diverse regional vegetation. These relationships are probably not the result of region-scale vegetation per se, but rather depends on whether specific requisites of natural enemies, as well as pests, are more or less likely to be present and accessible in a diverse spatial mosaic of habitats than in a landscape with few habitat types (Menalled et al., 1999). Because connecting specific resources to natural enemy performance is complex and often untenable from a regional perspective, ecological and management-based classification of vegetation structure and composition into broad categories (e.g., homogeneous versus heterogeneous vegetation, vegetation with and without floral resources) may be sufficient to gauge trends in natural enemy abundance and performance. 
These potential farm- and region-scale effects may be contingent upon seasonal shifts in vegetation, which are particularly relevant to agricultural landscapes of temperate climates. Vegetation structure and composition will change seasonally as patch quality of crop and noncrop vegetation changes with plant phenology and cultivation. Last, robustness of applying a landscape view across natural enemy functional and taxonomic groups is of ecological and land management interest. Landscape analyses built to address these issues may help assign (at least in sign if not in intensity) likely aphid-natural enemy outcomes associated with ecological and managementbased classification of vegetation structure and composition.

Here we consider the effects of scale and seasonal fluctuation in vegetation, using a winter wheat-cereal aphidparasitoid system from North America as a case example. In the west-central part of the North American Great Plains, winter wheat is the predominant dryland crop (USDA-NASS, 2005) and is embedded in a temperate grassland environment modified significantly by agriculture (Cunfer, 2005). In this region, an aphid pest of wheat, Diuraphis noxia (Mordvilko), the Russian wheat aphid, and its hymenopteran parasitoids occur with regularity (Brewer et al., 2001; Noma et al., 2005). We hypothesized that two spatial scales that are representative of two vegetation management approaches in North America (locally on the farm and regionally as affected by agricultural land use policies and programs) and seasonal shifts in vegetation will affect the abundance of parasitoids of $D$. noxia. We compared landscape analyses across two predominant parasitoids that represent the principal aphid parasitoid families (Hymenoptera: Aphelinidae and Braconidae, Aphidiinae), and reviewed the results in light of other aphid-natural enemy studies.

\section{MATERIAL AND METHODS}

\section{Farm- and region-scale vegetation of study area.}

The west-central part of the North American Great Plains (including southeast Wyoming, western Nebraska, and northcentral Colorado, USA) is a region of mixed grass prairie substantially modified by crop production (Cunfer, 2005). Our study was conducted in a $14,000 \mathrm{~km}^{2}$ area in which winter wheat is the predominant crop traditionally cultivated in a simple two-year wheat-fallow spatial rotation (Peterson et al., 1996). The rotation is composed of strips (30-90 m wide) of wheat and fallow that spatially alternate through commonly large fields of 250 ha or more. Some farmers have altered their wheat cropping by incorporating a spring-sown crop in the rotation, such as corn, oat, proso millet, or sunflower (farm-scale management) (Peterson et al., 1996). Regionally, large areas have been managed as pastures for animal grazing, planted with a seed mix that includes wheat grasses and other perennial grasses, which are hosts of D. noxia (Donahue et al., 2000). Also, wheat acreage has been converted into federallysponsored conservation grasslands which may include these host plants (Laycock, 1988). The region is further modified with other annual and forage crops where irrigation is available or soil and moisture conditions allow (Cunfer, 2005). The soil and climatic characteristics of the study area were described in Noma et al. (2005), and a full description of wheat production practices in this region was provided by Peterson et al. (1996).

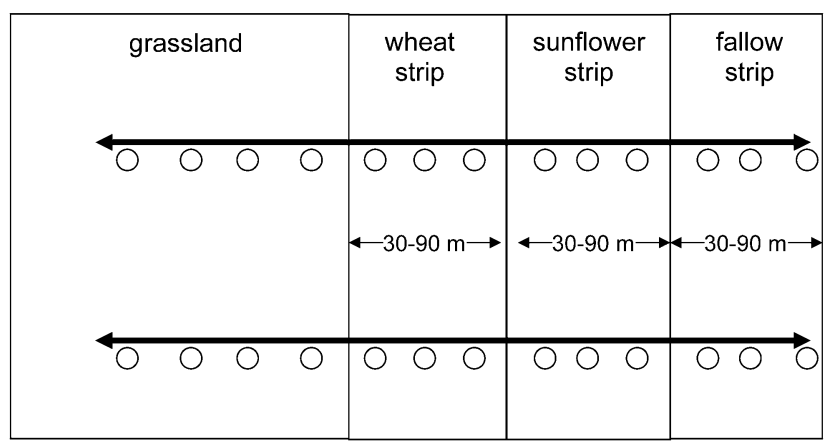

Fig. 1. General scheme of exposing D. noxia-infested potted winter wheat (circles) to field parasitism. Transects ran across the first three strips, always including at least one wheat strip, at least one fallow strip, and one sunflower strip where planted, and the opposite direction up to $150 \mathrm{~m}$ into an adjacent grassland.

As a result, variable spatial patterns of winter wheat (still the predominant crop of the region) with or without rotating strips of a spring-sown crop, other dryland and irrigated crops, and pastures and conservation grasslands embedded in the remnants of the original grassland region were available for study (Elliott et al., 1998a).

We located 16 wheat farms in 2001 and 2002 based on vegetation structure and composition within the farms (farm-scale) and within the greater region in which the farms were nested (region-scale). The farm sites consisted of a cropping area and an adjacent grassland area of either pasture or conservation grassland. The farm-scale landscape was vegetatively classified as simple and diverse farms, based on the crop rotation. In simple farms $(n=8)$, the crop rotation was a series of spatially alternating wheat (Triticum aestivum L.) and fallow strips. In diverse farms $(n=8)$, the cropping area consisted of a series of wheat, sunflower (Helianthus annuus L.), and fallow strips (Fig. 1). Plant growth stages of wheat and sunflower strips were recorded during farm visits.

The region-scale vegetation was characterized based on the percentage of grass-based and non-grass-based vegetation of a $25 \mathrm{~km}^{2}$ (5.6 $\mathrm{km}$ diameter) circular region surrounding the chosen farms. The selection of $25 \mathrm{~km}^{2}$ adequately captured surrounding vegetation patches which are typically perceived in US land survey units of $1.6 \mathrm{~km}$ by $1.6 \mathrm{~km}$ squares (sections) to $9.6 \mathrm{~km}$ by $9.6 \mathrm{~km}$ squares (townships) used for agricultural land use planning and reporting (USDA-NASS, 2005). We utilized a thematic map of the $14,000 \mathrm{~km}^{2}$ study area derived from satellite imagery taken by Landsat 7 ETM+ Scanner (United States Geological Survey, Reston, VA) in June and August 2000 (Brewer et al., 2008; Elliott et al., 1998a). The final thematic map depicted 12 land use classes categorized into grass-based vegetation (wheat, conservation grassland, pasture, and remnants of the original mixed grass prairie), non grass-based vegetation (sunflower, alfalfa, corn, millet), riparian areas, other non-managed vegetation, urban areas, and water. The thematic map had a $76 \%$ overall accuracy (ranging 50 to $100 \%$ accuracy for each land cover class) in matching randomly selected classified pixels with ground-truth data (Brewer et al., 2008).

Specific farm sites for the study were selected from a list of potential grower cooperators that farmed in the randomly drawn homogeneous $(n=8)$ and heterogeneous $(n=8)$ areas where both simple and diverse wheat farms occurred. Based on the thematic map, the homogeneous regions consisted of relatively large areas of grass-based vegetation $(74.4 \pm 4.0 \%$, combination of wheat, conservation grasslands, and other grasslands) and 
small areas of non-grass vegetation $(8.0 \pm 1.4 \%$, combination of other agriculture and riparian areas), while the heterogeneous regions consisted of smaller areas of grass-based vegetation $(52.9 \pm 3.0 \%)$ and larger areas of non-grass vegetation $(32.6 \pm$ $1.8 \%$ ) (Brewer et al., 2008).

\section{Sampling parasitoids and aphids}

Parasitoids were sampled at the 16 farm sites five times each year between late April and early October, bridging across spring regrowth of wheat and grassland to planting and emergence of fall-sown winter wheat (Fig. 1). Laboratory-reared $D$. noxia were exposed to field parasitism to obtain an estimate of their abundance (Noma et al., 2005). Briefly, plastic pots (16 $\mathrm{cm}$-diameter circle by $17 \mathrm{~cm}$ high) containing a dense layer of wheat seedlings (cultivar Buckskin) were infested with about 100 Russian wheat aphids. Thirty-two pots were placed at each farm site along two parallel line transects running perpendicular to the long axis of the crop strips and into the adjacent grassland (Fig. 1). Some aphid predation by predatory fly larvae was detected, but did not result in aphid depletion (Noma et al., 2005). Exposure to field parasitism was up to 7 days, until plant wilting was anticipated, and exposure time was consistent during each sampling period. The $D$. noxia-infested wheat was incubated in the greenhouse and emerging parasitoids were identified following the methodology described in Noma et al. (2005). Four pots were left in the laboratory concurrent to field exposure to check for parasitoid contamination: no contamination was detected. Two hymenopteran parasitoids, the aphelinid Aphelinus albipodus Hayat \& Fatima and the braconid Lysiphlebus testaceipes (Cresson), were the focus of this study, because they were the most abundant natural enemies, one $(A$. albipodus) had been implicated in suppressing Russian wheat aphid (Brewer et al., 2001; Brewer et al., 2005), and they represented the two principal aphid parasitoid families.

Naturally-occurring aphid populations in sunflower and wheat strips were sampled on the first day of each sampling period. Aphis helianthi was the only aphid species found on sunflower. Cereal aphids detected in wheat were D. noxia, Rhopalosiphum maidis (Fitch), Rhopalosiphum padi L., and Schizaphis graminum (Rondani). Leaf-feeding aphids were not detected in the adjacent grasslands (Brewer et al., 2005). Sunflower plants ( $n=$ 60 per farm site) in diverse cropping sites were randomly selected along the two line transects and were inspected for aphids on every leaf. Randomly selected wheat tillers $(n=100$ per farm site) were inspected for presence of aphids along the two line transects.

\section{Experimental measurement, design, and analyses}

As measurement of the two parasitoids' potential to suppress $D$. noxia, detection frequency of parasitism was used: the percent of pots in each farm site in which $D$. noxia parasitism of each parasitoid was detected. This frequency measurement was highly correlated with total number of parasitoids per pot (Brewer et al., 2005), but we chose the detection frequency measurement because it clearly controls for variability in differences in oviposition rates among individual parasitoids. Percent of sunflower plants infested with A. helianthi, percent of wheat tillers infested with $D$. noxia, and percent of wheat tillers infested with other cereal aphids were used as estimates of aphid abundance in the wheat production system.

The study was designed as a two (farm-scale vegetation) by two (region-scale vegetation) factorial. The four treatment combinations were diverse farm set within a heterogeneous region, simple farm set within a heterogeneous region, diverse farm set within a homogeneous region, and simple farm set within a homogeneous region. They were replicated four times and

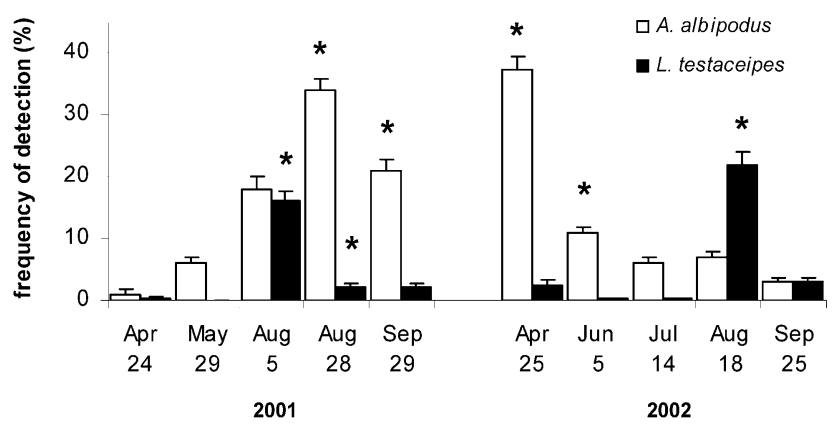

Fig. 2. Overall detection rates of two parasitoids of D. noxia in west-central Great Plains during the two study years. Asterisks indicate when significant effects of farm-scale and regional-scale vegetation were detected $(P<0.05)$. Error bars represent standard errors of means.

grouped into complete blocks covering the $14,000 \mathrm{~km}^{2}$ study area (Noma et al., 2005). Crop selection by growers was partly dependent upon potential crop growth dictated by moisture and soil conditions (Peterson et al., 1996). Therefore the treatments were not strictly randomized in the study region but allowed interpretation relevant to the regional ecology and agriculture of interest [see Hargrove \& Pickering (1992) for relevance to regional ecology].

The detection frequency of $D$. noxia parasitoids was analyzed separately for A. albipodus and L. testaceipes with sampling dates treated as a repeated measures factor. The results were viewed seasonally to relate to shifts in vegetation from early season (two dates, April through June) to late season (three dates, July through September) (Fig. 2). An analysis of variance for a two (farm-scale vegetation) by two (region-scale vegetation) factorial (fixed effects) blocked design was used with a logistic function for binomial data (PROC GLIMMIX, SAS Institute, 2006). When significant interactions between the farm-scale and region-scale vegetation effects on parasitoids were detected within a sampling period, $t$ tests were used for mean separation of detection frequency of parasitism (PROC GLIMMIX, SAS Institute, 2006).

The potential relationship of aphid and parasitoid measures was investigated by using aphid abundance as a covariate in the analysis following the procedures of Milliken \& Johnson (2002). Because delayed response by parasitoid populations to the changes in aphid density was expected (Jervis, 2005), aphid measurements during one sampling period were coupled with parasitoid measurements from the preceding sampling period roughly one mo later. $D$. noxia and $A$. helianthi were used but not data for other cereal aphids, which were rarely detected only in the last sampling period of both years (Brewer et al., 2005). $D$. noxia and $A$. helianthi as covariates were incorporated separately into the analysis, and data across all sampling dates within each study year were included to capture the full range of aphid measurements. Regression analyses (PROC REG, SAS Institute, 2004) were used to analyze the pattern of aphid covariate-parasitoid associations when detected. The interaction of farm- and region-scale vegetation on aphid covariateparasitoid associations were considered first, and simple covariate-parasitoid functions were considered if no interaction was detected.

\section{RESULTS}

During 10 sampling periods over the two study years, detection frequency of the two parasitoids, A. albipodus and $L$. testaceipes, ranged from a farm site average $(n=$ 

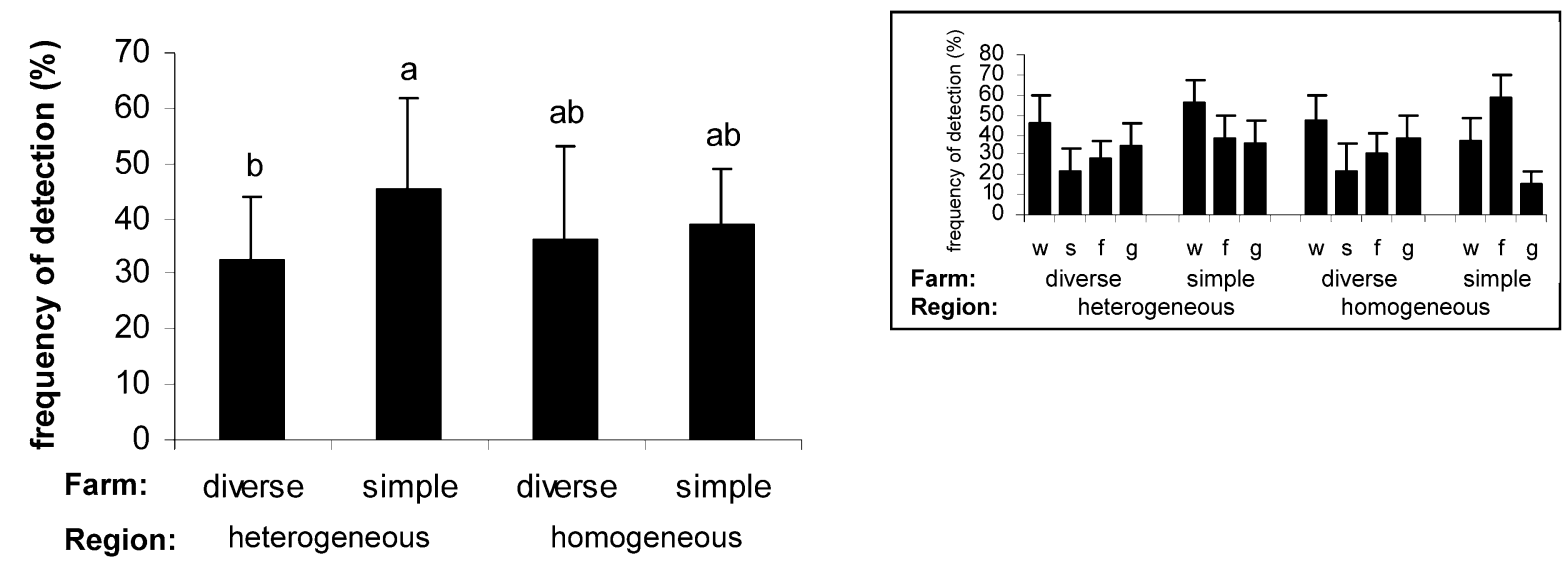

b

\section{A. albipodus, Jun 5, 2002}
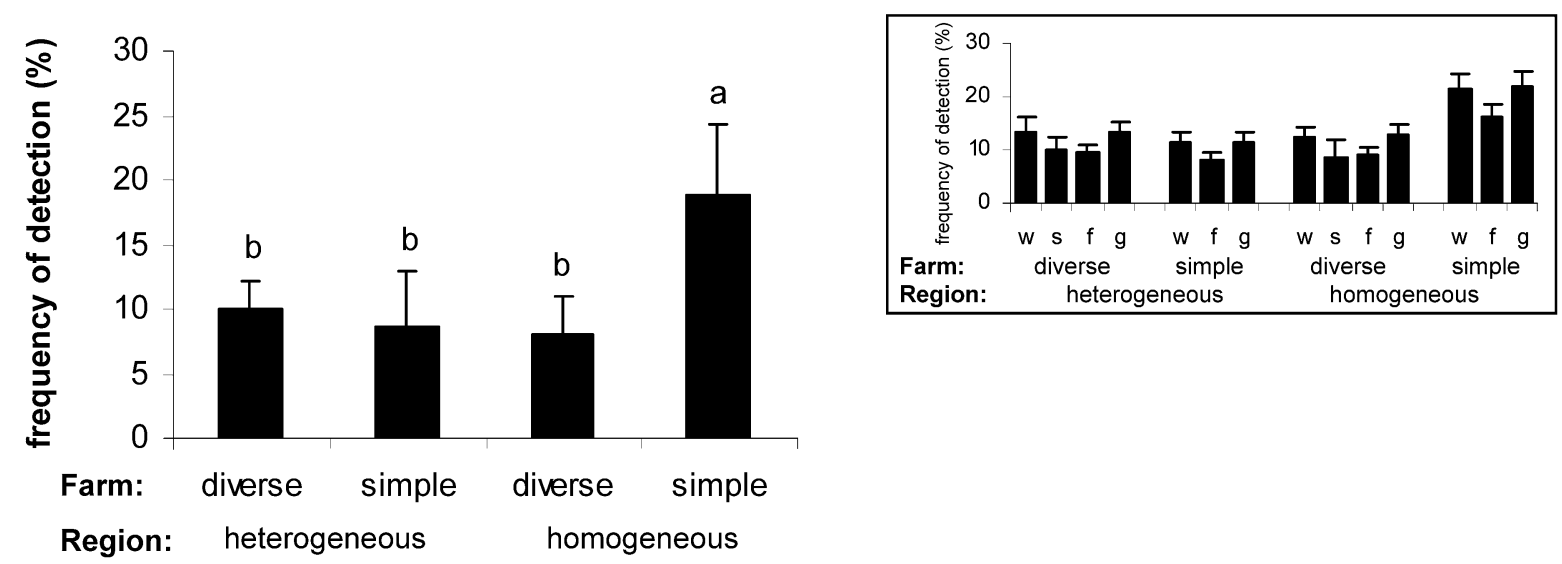

Fig. 3. April through June comparisons of A. albipodus detection across region-scale (heterogeneous and homogeneous) and farmscale (diverse and simple farms) vegetation classes. Early season plant growth from wheat and grassland regrowth and early sunflower establishment through wheat maturation and sunflower and grassland vegetative growth. Statistically significant cases are featured and views of means of all treatment combinations and field types ( $\mathrm{w}$ - wheat; $\mathrm{s}$ - sunflower; $\mathrm{f}$ - fallow; $\mathrm{g}$ - grassland) are inserted in a box. Different letters in the featured graph indicate significant differences between means. Error bars represent standard errors of means.

16) of 0 to $38 \%$ of exposed pots (individual farm site range was 0 to $63 \%$ ) (Fig. 2). The analysis of variance with repeated measures for each parasitoid revealed significant three-way interaction among farm-scale vegetation, region-scale vegetation, and sampling date ( $A$. albipodus: $F=3.09 ; \mathrm{df}=9,113 ; P=0.002 ; L$. testaceipes: $F=2.61 ; \mathrm{df}=9,113 ; P=0.009)$. These results indicated that there were seasonal shifts in the vegetative diversity-parasitoid relationships. These relationships were assessed for each sampling period (Fig. 2), to interpret the seasonal dynamics of vegetative diversityparasitoid relationships.

\section{Seasonal dynamics of parasitoid prevalence}

Early season sensitivity to farm-scale and region-scale vegetation was detected only for A. albipodus in 2002 . During the early season period of wheat maturation and sunflower establishment in April, A. albipodus was detected more frequently in simple farms than diverse farms within heterogeneous landscapes $(t=2.25$, df $=$
113, $P=0.02$, Fig. 3a), but $A$. albipodus was found at similar frequencies between simple and diverse farms within homogeneous landscapes $(t=0.89$, $\mathrm{df}=113, P=$ 0.38 ). The parasitoid tended to be found more frequently in wheat strips compared with sunflower strips and grasslands (see boxed graph of Fig 3a for perspective). During the next sampling period as wheat matured and sunflower and grasslands were growing vegetatively (June 2002), $A$. albipodus was more frequently detected in simple farms than diverse farms within the homogeneous regions $(t=$ 2.55 , df $=113, P=0.01$, Fig. $3 \mathrm{~b}$ ); whereas, $A$. albipodus was detected at similar frequencies in diverse and simple farms in the heterogeneous regions $(t=0.33, \mathrm{df}=113, P$ $=0.74$, Fig. $3 \mathrm{~b}$ ). Overall, wheat farming incorporating sunflower strips did not appear to benefit this parasitoid nor $L$. testaceipes (no treatment effects detected, $P>$ 0.05 ), during this early season period. The more frequent detection of $A$. albipodus in simple farms nested in the homogeneous regions in June (Fig. 3b) was most likely a 

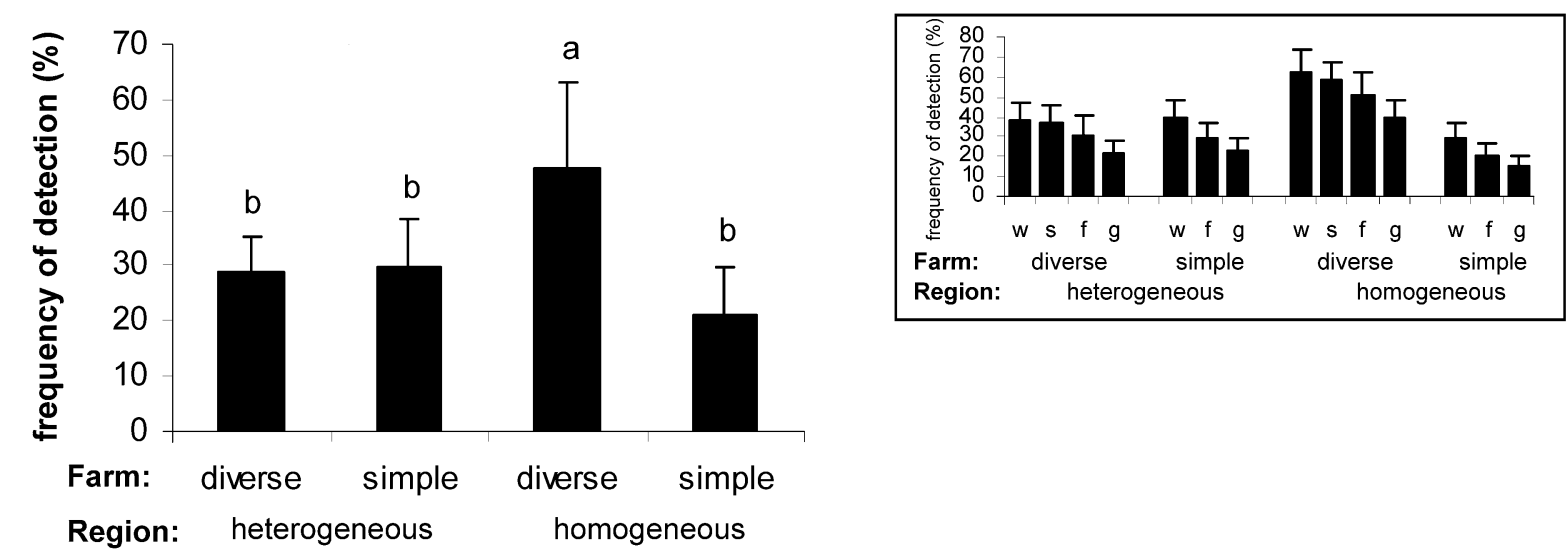

b

A. albipodus, Sep 29, 2001
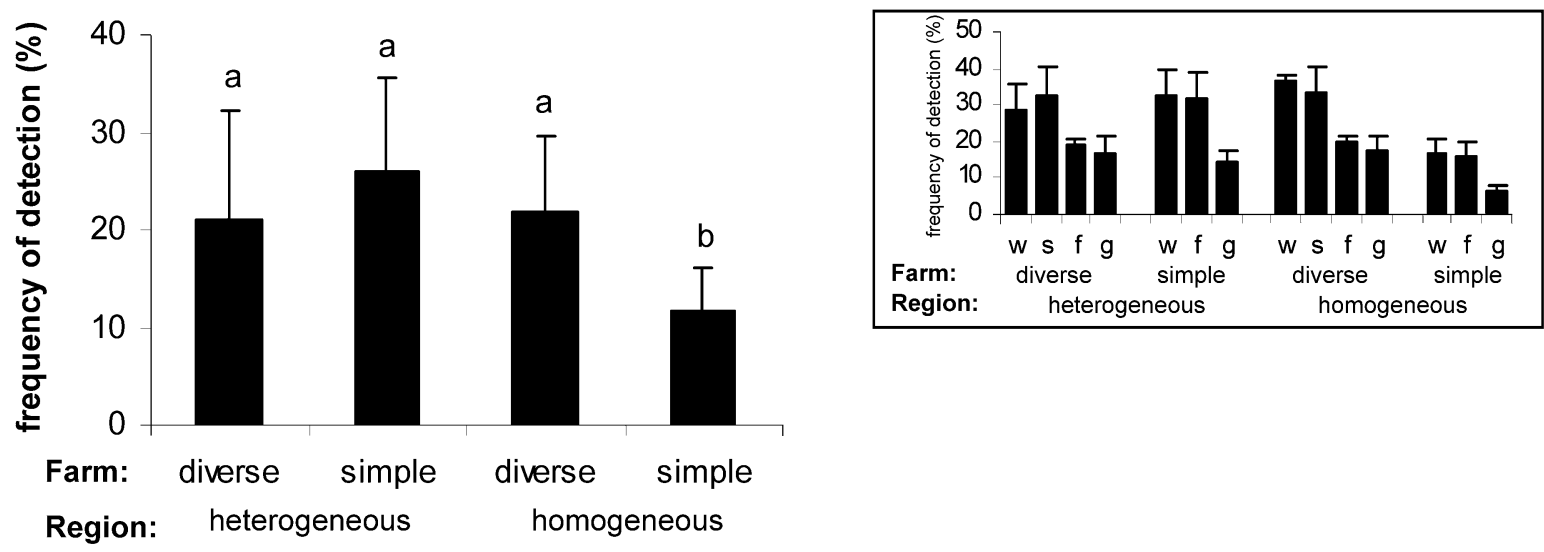

Fig. 4. August through October comparisons of A. albipodus detection across region-scale (heterogeneous and homogeneous) and farm-scale (diverse and simple farms) vegetation classes. Late season plant growth bridging across wheat harvest, sunflower and grassland maturation, and replanting of wheat. Statistically significant cases are featured and views of means of all treatment combinations and field types ( $\mathrm{w}$ - wheat; $\mathrm{s}$ - sunflower; $\mathrm{f}$ - fallow; $\mathrm{g}$ - grassland) are inserted in a box. Different letters in the featured graph indicate significant differences between means. Error bars represent standard errors of means.

response of unusually high abundance of $D$. noxia, $>10 \%$ D. noxia-infested wheat tillers in two of four simple farms nested in the homogeneous regions.

Late season sensitivity to farm-scale and region-scale vegetation was detected for both parasitoids in 2001 and for L. testaceipes in 2002. During the late season period of wheat harvest, sunflower and grassland maturation, and replanting of wheat in 2001, A. albipodus was detected more frequently in diverse than simple farms within the homogeneous regions $(t=4.43, \mathrm{df}=113, P=$ 0.0001 , Fig. $4 \mathrm{a} ; t=2.71, \mathrm{df}=113, P=0.008$, Fig. $4 \mathrm{~b}$ ). But in the heterogeneous regions, frequency of detecting A. albipodus was similar between diverse and simple farms $(t=0.09$, df $=113, P=0.93$, Fig. $4 \mathrm{a} ; t=0.77$, df $=$ $113, P=0.45$, Fig. 4b). During the same two sampling periods, $A$. albipodus tended to be detected in sunflower strips as high as in other crop strips and higher than in adjacent grasslands (see boxed graphs of Fig. 4a and Fig. $4 \mathrm{~b}$ for perspective).

During early and late August 2001, L. testaceipes was detected more frequently in diverse than simple farms within the homogeneous regions $(t=2.63$, $\mathrm{df}=113, P=$ 0.01 , Fig. 5a; $t=2.04$, df $=113, P=0.04$, Fig. 5b); whereas within the heterogeneous regions, the farm-scale effect was not significant $(t=1.12$, df $=113, P=0.26$, Fig. 5a; $t=0.41, \mathrm{df}=113, P=0.68$, Fig. 5b). The next year in mid-August 2002, L. testaceipes was still recovered more frequently in diverse than simple farms but this occurred only in the heterogeneous regions $(t=3.39, \mathrm{df}=$ $113, P=0.001$, Fig 5c). L. testaceipes was detected least frequently in sunflower strips within the heterogeneous regions; whereas in the homogeneous regions, the parasitoid was as common in sunflower as in the other crop strips and was less common in the grasslands (see boxed graph of Fig. 5c for perspective). Overall for the late season period, wheat farming diversified with sunflower strips was associated with increased parasitoid prevalence four times within the homogeneous regions and once within the heterogeneous regions. Aphelinus albipodus was detected frequently in sunflower strips, while detection of L. testaceipes in sunflower varied greatly depending on surrounding regional-scale vegetation. 

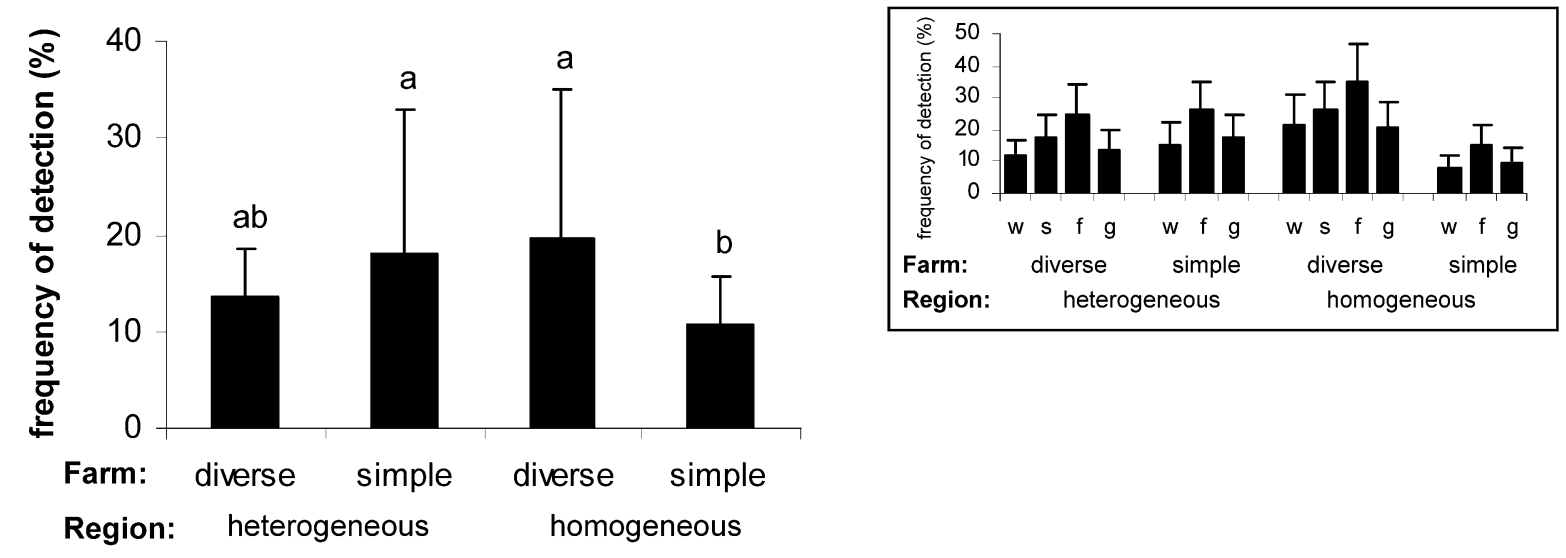

b

L. testaceipes, Aug 18, 2001
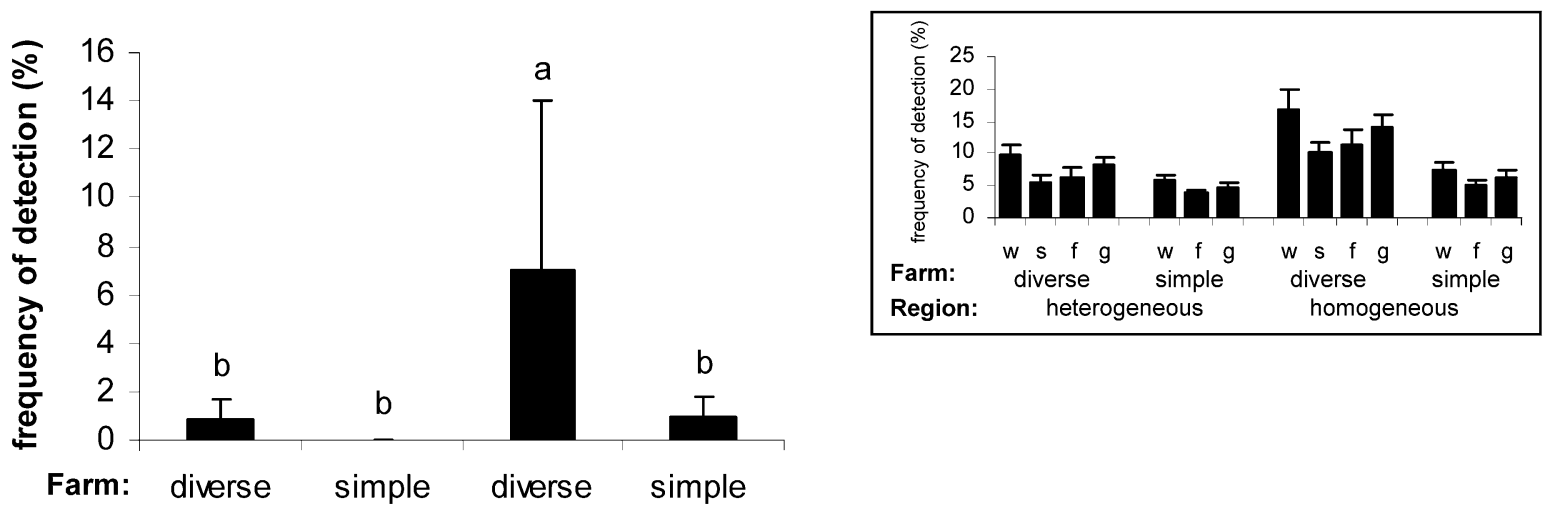

Farm: diverse simple

homogeneous

C

\section{L. testaceipes, Aug 18, 2002}
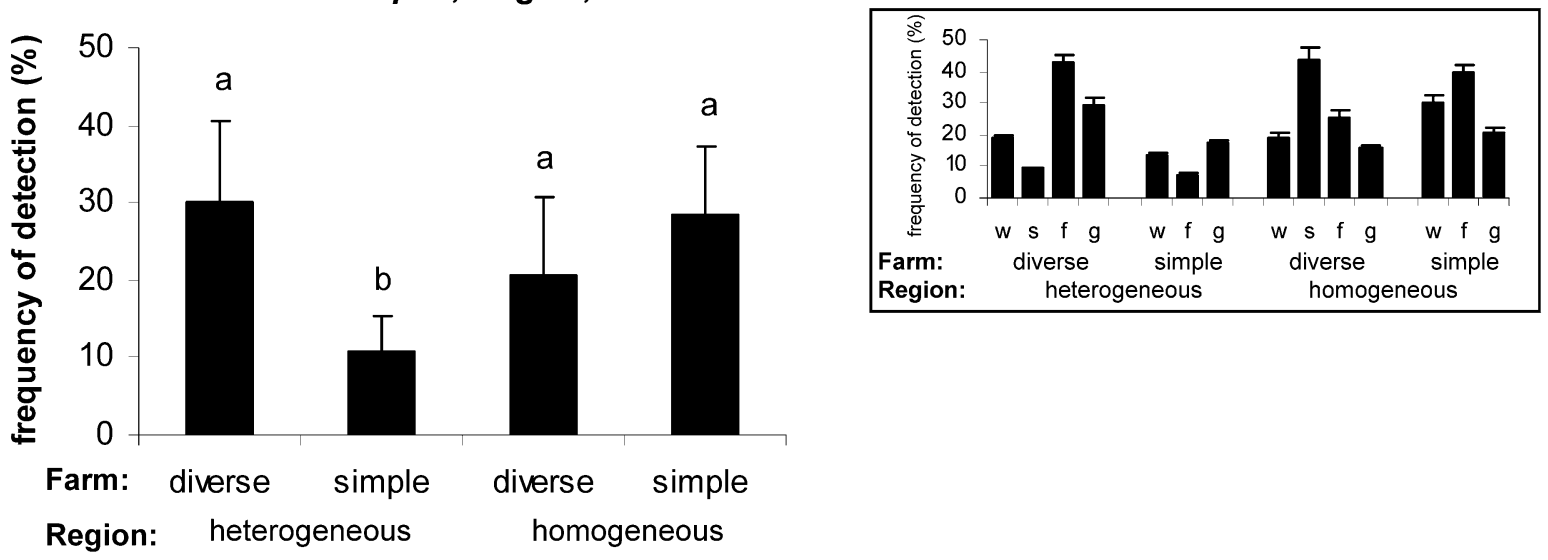

Fig. 5. August through October comparisons of L. testaceipes detection across region-scale (heterogeneous and homogeneous) and farm-scale (diverse and simple farms) vegetation classes. Late season plant growth bridging across wheat harvest, sunflower and grassland maturation, and replanting of wheat. Statistically significant cases are featured and views of means of all treatment combinations and field types ( $\mathrm{w}$ - wheat; $\mathrm{s}$ - sunflower; $\mathrm{f}$ - fallow; $\mathrm{g}$ - grassland) are inserted in a box. Different letters in the featured graph indicate significant differences between means. Error bars represent standard errors of means.

Parasitoid association with aphids mediated by farmand region-scale effects

Using the data from the diverse crop rotations where $A$. helianthi on sunflower occurred, the A. helianthi- parasitoid association was best described as simple functions in 2001, but the association differed for the two parasitoids. A. albipodus increased considerably as detection of $A$. helianthi increased (slope $=2.35, R^{2}=0.44, \chi^{2}$ 
a

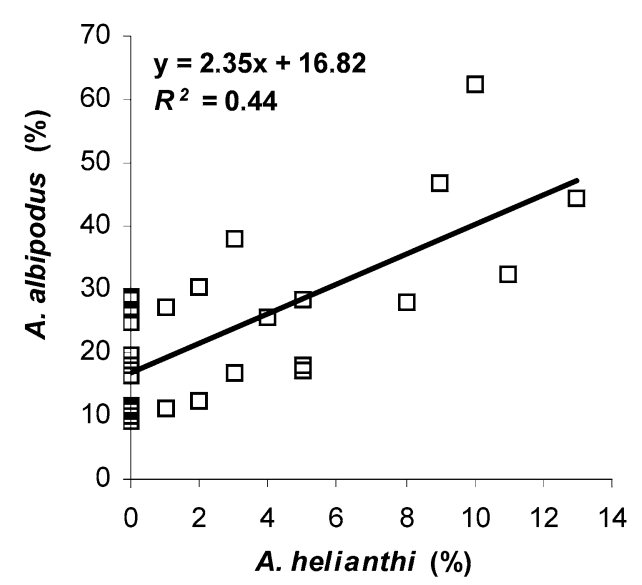

C

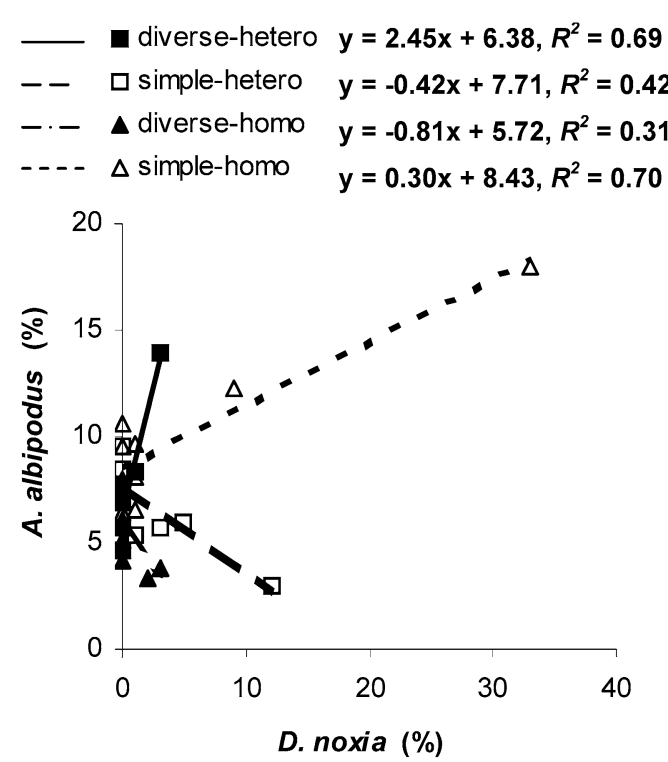

b 2001

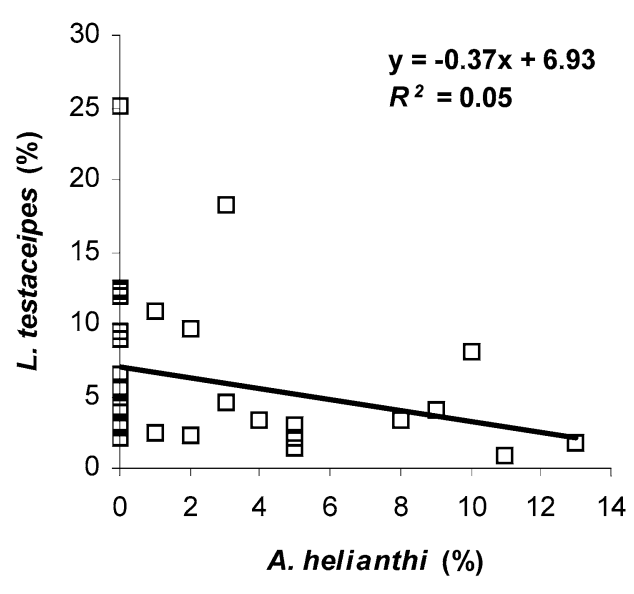

d 2002

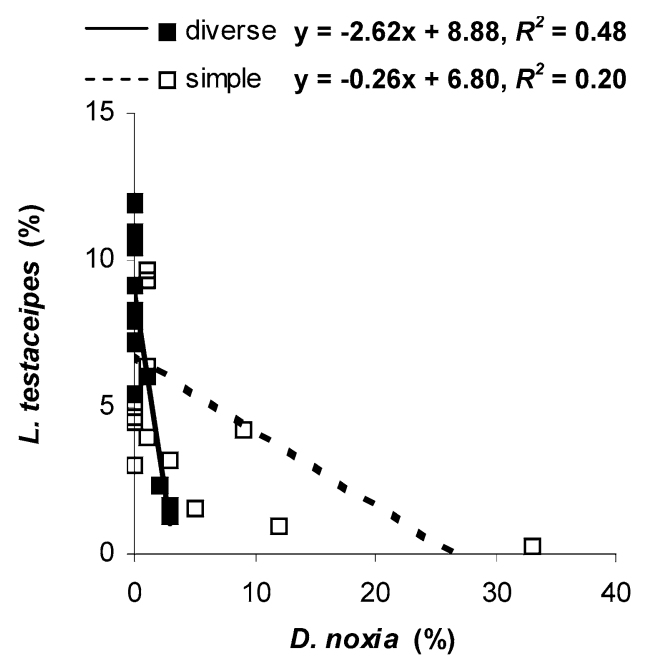

Fig. 6. Parasitoid (A. albipodus or L. testaceipes) prevalence (detection frequency of parasitism) associated with shifts in aphid abundance (percent of sunflower plants infested with $A$. helianthi or percent of wheat tillers infested with $D$. noxia) estimated one month before. Only significant associations were plotted. Significant interactions across the vegetation diversity gradient [farm-scale: diverse and simple vegetation; region-scale: heterogeneous (hetero) and homogeneous (homo) vegetation classes] were considered first, and simple covariate-parasitoid functions were plotted if no interaction was detected.

$=43.38, \mathrm{df}=1, P=0.0001$, Fig. $6 \mathrm{a})$, while detection frequency of $L$. testaceipes had minimal change as $A$. helianthi detection increased (slope $=-0.37, R^{2}=0.05, \chi^{2}=$ 10.60 , df $=1, P=0.001$, Fig. 6b). No A. helianthiparasitoid associations were detected in 2002 when the aphid was rare (Brewer et al., 2005). D. noxia was rarely detected in 2001 (Brewer et al., 2005), and no sensitivity of the analysis to D. noxia was found. In 2002, differential sensitivity across the farm-scale and region-scale vegetation gradient was detected in the $D$. noxia- $A$. albipodus association $\left(\chi^{2}=3.10, \mathrm{df}=1, P=0.07\right)$ (Fig. 6c) and D. noxia - L. testaceipes association $\left(\chi^{2}=3.91, \mathrm{df}=1\right.$, $P=0.05$ ) (Fig. 6d). The interpretation of the sensitivity suffered from $D$. noxia densities occurring mostly over a narrow range, with only three instances of $D$. noxia $>$ $10 \%$ infested wheat tillers (a common economic threshold). It is noteworthy that two of these instances of high $D$. noxia abundance were associated with high $A$. albipodus detections, as has been previously reported (Brewer et al., 2005), but L. testaceipes detections were consistently low (Fig. 6cd).

\section{DISCUSSION}

\section{Parasitoid sensitivity to farm- and region-scale vegetation}

Aphelinus albipodus and L. testaceipes were sensitive to farm-scale vegetation, and region-scale vegetation to a lesser extent in good part through interaction with farmscale vegetation. Using a focal point approach in which the response variables were regressed against landscape variables across different scales, Thies et al. (2005) determined that landscape structure at the spatial extent of 
$0.5-2 \mathrm{~km}$ had significant influence on cereal aphid parasitoids. We structured our experiments in a factorial design of the spatial scale allowing assessment of joint effects of farm- and region-scales on parasitoid prevalence: farmscale which approximates the Thies et al. (2005) finding and region-scale which is more pertinent to regional agricultural land use planning and programs. With the factorial design, a farm- and region-scale interaction indicated that regional effects of a greater spatial extent were also relevant in aphid parasitoid ecology. Specifically, the addition of a spring-sown crop in the wheat-fallow rotation benefited aphid parasitoids, and this was particularly helpful in the homogeneous vegetation regions.

\section{Seasonal dynamics of the effects of farm- and region-scale vegetation}

Seasonal dynamics may be particularly relevant for organisms of relatively short life-span like aphids and parasitoids and for temperate zone agricultural landscapes in which patch composition and patch qualities are seasonally affected by cultivation practices and plant phenology. During the early season, winter wheat availability for $D$. noxia appeared to be a principal driver affecting $A$. albipodus, particularly in simple farms of homogeneous regions. This result was in apparent contrast to Vorley \& Wratten (1987) and Wratten \& Powell (1990), who found that early-maturing plants such as ryegrass in grasslands, barley, and early-sown wheat act as reservoirs of aphid parasitoids in the spring, and these parasitoids migrate into nearby late-sown wheat. But our early season vegetation conditions differed considerably. Winter wheat production systems of the west-central North American Great Plains diversified with late-maturing plants of spring-sown crops provided no addition to the plant community early season; therefore the percent of land with vegetative cover and with habitat favorable to $D$. noxia and its parasitoids was higher in simple farms (about 50\% of the farm is winter wheat) than diverse farms (about $33 \%$ wheat).

The value of adding a spring-sown crop and the interaction with region-scale vegetation became apparent during summer, when sunflower was vigorously growing. The positive effects of incorporating sunflower strips was observed for both $A$. albipodus and L. testaceipes, most apparently in homogeneous vegetation regions. Our late season results were agreeable with a number of other studies that found positive effects of habitat diversification on arthropod natural enemies at farm- and regionalscales (Altieri et al., 1993; Colunga-Garcia et al., 1997; Elliott et al., 1998b; Marino \& Landis, 1996; Powell, 1986; Schmidt et al., 2004; Thies et al., 2005).

\section{Robustness of application of findings for two parasitoids of $D$. noxia}

Lysiphlebus testaceipes is more mobile and does not aphid host feed (Kaiser et al., 2007; Pike et al., 2000). Aphelinus albipodus, a representative Aphelinus spp., is less mobile and does aphid host feed (Elliott et al., 1999; Kaiser et al., 2007). In addition, L. testaceipes has a much broader host aphid range than A. albipodus (Kaiser et al.,
2007; Pike et al., 2000). Therefore, L. testaceipes may be more sensitive to region-scale vegetation, while $A$. albipodus responsiveness to vegetation may not extend beyond the farm-scale strategy to add a spring-sown grain to wheat-fallow rotation. We generally found our results in agreement with this hypothesis. Sensitivity to regionscale vegetation and its interaction with farm-scale effects, were more apparent for L. testaceipes, particularly in the late season (Fig. 5); while A. albipodus sensitivity to farm-scale effects was more predominate, particularly in the early season (Figs 3 and 4).

Overall, the study of aphid parasitoid ecology would benefit from a landscape view of scale and seasonal effects of vegetation, although an emphasis on farm-scale factors seems justified (Wratten \& Powell, 1990). In our study, a factorial design of farm-scale and region-scale provided the additional insight that the effects of local habitat arrangement on biological control agents (in our case addition of sunflower into the wheat-fallow rotation) were particularly important in simple and less so in complex regional landscapes, as consistent with Tscharntke \& Brandl (2004). Considerable sensitivity of the analysis was added when adjusting for seasonality of vegetation, showing that the region-scale effects were most prominent late season. From a management viewpoint, adding sunflower into the wheat production system, especially when set in relatively homogeneous region-scale vegetation, tends to promote local parasitoid populations during the summer when spring-sown plants are maturing and wheat is not in cultivation. The contrasting results for $A$. albipodus and L. testaceipes were consistent with expectations based on behavioral and physiological attributes of the two aphid parasitoid families they represent. Still, the general management interpretation seems robust for the two parasitoids and has relevance to both farm-scale (crop diversity managed by wheat farmers) and regionscale (degree of diversification of the original grassland region with other crops and grower participation in conservation programs designed to convert wheat fields to grasslands) management schemes that are occurring in the wheat production zone of the North American Great Plains.

ACKNOWLEDGEMENTS. We thank M. DeWine, S. Grabowski, K. Hoff, A. Kelsey, and S. Yan (University of Wyoming) for their assistance. We also thank G. Hein (University of Nebraska) and F. Peairs (Colorado State University) for their assistance in finding farm sites for this study, and R. Baumgartner and C. Pexton (University of Wyoming) for maintaining one of the sampling sites during this study. We thank grower cooperators for access to their properties. This study was financially supported by the USDA CSREES National Research Initiative, Biologically-based Pest Management program (2000-02559 and 2002-04573).

\section{REFERENCES}

AHERn R.G. \& BRewER M.J. 2002: Effect of different wheat production systems on the presence of two parasitoids (Hymenoptera: Aphelinidae; Braconidae) of the Russian wheat aphid in the North American Great Plains. Agric. Ecosyst. Environ. 92: 201-210. 
Altieri M.A., Cure J.R. \& Garcia M.A. 1993: The role and enhancement of parasitic Hymenoptera biodiversity in agroecosystems. In LaSalle J. \& Gauld I.D. (eds): Hymenoptera and Biodiversity. CAB International, Oxon, pp. 257-275.

Brewer M.J., Nelson D.J., Ahern R.G., Donahue J.D. \& PROKRYM D.R. 2001: Recovery and range expansion of parasitoids (Hymenoptera: Aphelinidae and Braconidae) released for biological control of Diuraphis noxia (Homoptera: Aphididae) in Wyoming. Environ. Entomol. 30: 578-588.

Brewer M.J., Noma T. \& Elliott N.C. 2005: Hymenopteran parasitoids and dipteran predators of the invasive aphid Diuraphis noxia after enemy introductions: temporal variation and implication for future aphid invasions. Biol. Control 33: 315-323.

Brewer M.J., Noma T. \& Elliott N.C. 2008: A landscape perspective in managing vegetation for beneficial plant-pestnatural enemy interactions: a foundation for areawide pest management. In Koul O., Cuperus G. \& Elliott N. (eds): Areawide pest management: theory and implementation. CABI, London, pp. 81-96.

Colunga-Garcia M., Gage S.H. \& Landis D.A. 1997: Response of an assemblage of Coccinellidae (Coleoptera) to a diverse agricultural landscape. Environ. Entomol. 26: 797-804.

Cowgill S.E., Wratten S.D. \& Sotherton N.W. 1993: The effects of weeds on the numbers of hoverfly (Diptera: Syrphidae) adults and the distribution and composition of their eggs in winter wheat. Ann. Appl. Biol. 123: 499-515.

Cunfer G. 2005: On the Great Plains: Agriculture and Environment. Texas A\&M University Press, College Station, 292 pp.

Donahue J.D., Brewer M.J. \& Burd J.D. 2000: Relative suitability of crested wheatgrass and other perennial grass hosts for the Russian wheat aphid (Homoptera: Apididae). J. Econ. Entomol. 93: 323-330.

Elliott N.C., Hein G.L., Carter M.R., Burd J.D., Holtzer T.O., Armstrong J.S. \& Waits D.A. 1998a: Russian wheat aphid (Homoptera: Aphididae) ecology and modeling in Great Plains agricultural landscapes. In Quisenberry S.S. \& Peairs F.B. (eds): Response Model for an Introduced Pest the Russian Wheat Aphid. Proceedings Thomas Say Publications in Entomology. Entomological Society of America, Lanham, MD, pp. 31-64.

Elliott N.C., Kieckhefer R.W., Lee J.-H. \& French B.W. 1998b: Influence of within-field and landscape factors on aphid predator populations in wheat. Landsc. Ecol. 14: 239-252.

Elliott N.C., Lee J.H. \& Kindler S.D. 1999: Parasitism of several aphid species by Aphelinus asychis (Walker) and Aphelinus albipodus Hayat and Fatima. Southwest. Entomol. 24: $5-12$.

Hargrove W.W. \& Pickering J. 1992: Pseudoreplication: a sine qua non for regional ecology. Landsc. Ecology 6: 251-258.

Jervis M.A. 2005: Insects as Natural Enemies, a Practical Perspective. Springer, Dordrecht, $748 \mathrm{pp}$.

Kaiser M.E., Noma T., Brewer M.J., Pike K.S., Vockeroth J.R. \& GAIMARI S.D. 2007: Hymenopteran parasitoids and dipteran predators found using soybean aphid after its Midwestern United States invasion. Ann. Entomol. Soc. Am. 100: 196-205
LAYCOCK W.A. 1988: History of grassland plowing and grass planting on the Great Plains. In: Impacts of the Conservation Reserve Program in the Great Plains. USDA Forest Service, General Technical Report RM-158, Denver, CO, pp. 3-8.

Marino P.C. \& LANDIS D.A. 1996: Effect of landscape structure on parasitoid diversity and parasitism in agroecosystems. Ecol. Appl. 6: 276-284.

Menalled F.D., Marino P.C., Gage S.H. \& Landis D.A. 1999: Does agricultural landscape structure affect parasitism and parasitoid diversity? Ecol. Appl. 9: 634-641.

Milliken G.A. \& Johnson D.E. 2002: Analysis of Messy Data Vol. 3: Analysis of Covariance. Chapman \& Hall/CRC, Boca Raton, FL, $605 \mathrm{pp}$.

Noma T., Brewer M.J., Pike K.S. \& Gaimari S.D. 2005: Hymenopteran parasitoids and dipteran predators of Diuraphis noxia in the west-central Great Plains of North America: species records and geographic range. BioControl 50: 97-111.

Peterson G.A., Schlegel A.J., Tanaka D.L. \& Jones O.R. 1996: Precipitation use efficiency as affected by cropping and tillage systems. J. Prod. Agric. 9: 180-186.

Pike K.S., Starý P., Miller T., Graf G., Allison D., Boydston L. \& Miller R. 2000: Aphid parasitoids (Hymenoptera: Braconidae: Aphidiinae) of northwest USA. Proc. Entomol. Soc. Wash. 102: 688-740.

Powell W. 1986: Enhancing parasitoid activity in crops. In Waage J. \& Greathead D. (eds): Insect Parasitoid. Academic Press, London, pp. 319-340.

Rogers C.E. 1985: Extrafloral nectar: entomological implications. Bull. Entomol. Soc. Am. 31: 15-20.

SAS Institute 2004: SAS / STAT User's Guide, Version 9.1. SAS Institute, Cary, NC, 5180 pp.

SAS Institute 2006: The GLIMMIX Procedure, June 2006. SAS Institute, Cary, NC, $256 \mathrm{pp}$.

Schmidt M.H., Thies C. \& TscharntKe T. 2004: Landscape context of arthropod biological control. In Gurr G.M., Wratten S. D. \& Altieri M.A. (eds): Ecological Engineering for Pest Management. Cornell University Press, Ithaca, pp. 55-63.

Thies C., Roschewitz I. \& Tscharntke T. 2005: The landscape context of cereal aphid-parasitoid interactions. Proc. R. Soc. (B) 272: 203-210.

TscharntKe T. \& Brandl R. 2004: Plant-insect interactions in fragmented landscapes. Annu. Rev. Entomol. 49: 405-430.

USDA-NASS 2005: Agricultural Statistics Database. http://www.nass.usda.gov/Census_of_Agriculture/index.asp. USDA-NASS, Washington, D.C. Cited 20 APR 2005.

VORLEY V.T. \& WRATten S.D. 1987: Migration of parasitoids (Hymenoptera: Braconidae) of cereal aphids (Hemiptera: Aphididae) between grassland, early-sown cereals and latesown cereals in southern England. Bull. Entomol. Res. 77: 555-568.

Wratten S.D. \& Powell W. 1990: Cereal aphids and their natural enemies. In Firbank L.G., Darbyshire J.F. \& Potts G.R. (eds): The Ecology of Temperate Cereal Fields. Blackwell Scientific Publications, London, pp. 233-257.

Received September 18, 2007; revised and accepted January 14, 2008 